NEOGI AND ADHICĀRY :

\title{
XIV.-Preparation of Ammonium Nitrite by the Sublimation in a Vacuum of a Mixture of Ammonium Chloride and Alkali Nitrites.
}

By Pañchānan Neogi, M.A., and Birendra Bhusan Adhicāry, M.A.

RÂY (Trans., 1909, 95, 345) has recently shown that solid ammonium nitrite sublimes in small quantities with decomposition when a dilute solution $(0.7$ to 2.0 per cent.) of the salt, obtained by the double decomposition of silver or barium nitrite and ammonium chloride or sulphate respectively, is gently heated in a vacuum. We have now found that the salt may be obtained in fairly large quantities by evaporating and subliming in a vacuum a very concentrated solution of a mixture of ammonium chloride and sodium or potassium nitrite.

\section{Experimental.}

The apparatus employed is as follows. A distilling flask of fairly large capacity is connected with a condenser, to the other end of which are attached two filtering flasks connected with each other by means of pressure tubing, and immersed in cold water. The first serves as a receiver, and the second, which contains a quantity of concentrated sulphuric acid, is connected with a manometer and a Geryk pump. The flask is heated in a water- or, better, paraffinbath.

Twenty-three grams of ammonium chloride and 35 grams of sodium nitrite (or 42 grams of potassium nitrite) were dissolved in the minimum quantity of cold water, the solution transferred to the distilling flask, the latter connected with a condenser, and the Geryk pump set to work. The flask was immersed in a paraffin-bath up to the portion containing the solution, and the temperature of the bath was maintained between $50^{\circ}$ and $60^{\circ}$. Water distilled with gentle frothing, but without bumping. Considerable bumping, however, takes place if a naked flame is used instead of a bath. The filtering flasks dipped in cold water arrested any escaping moisture, which would otherwise enter the pump and condense in the manometer. When a certain concentration was reached, minute bubbles of gas were evolved, and the mercury column descended slightly. The pump was worked from time to time to maintain the vacuum. Special care should be taken at the time when the mass just becomes solid. At this point the temperature should not be raised above $60^{\circ}$, and the pump should be constantly worked, as otherwise the whole of the nitrite would decompose with almost 
explosive violence. When once the mass has solidified and become perfectly quiescent, the liability of the nitrite to decompose is almost removed. The temperature of the bath was then gradually raised to $80^{\circ}$, when the solid nitrite began to sublime.* The flask was gradually lowered into the bath as the sublimate rose higher and higher, until the whole mass was collected as a thick, circular crust at the top of the bulb of the flask. The bath was then removed, and air was admitted, not by opening the screw in the pump (as in that case the moist air would dissolve the whole quantity of the extremely hyggroscopic nitrite formed), but by gently opening the cork of the flask. The bottom of the latter was then broken, and the solid mass quickly scraped off with a spatula. The substance was so very deliquescent that it was difficult to remove the whole quantity of the salt obtained. A considerable portion of the salt decomposed, and a part escaped into the condenser with the steam. The liquid collected in the receiver contained much ammonium nitrite as well as a small quantity of the chloride.

The liquid in the receiver was transferred to the distilling flask, and evaporated in a vacuum as before. A second crop of the nitrite sublimed, and was collected.

\section{Analysis.}

The substance obtained consists of fine flakes, and is extremely hygroscopic. It liberates iodine copiously when treated with potassium iodide solution acidified with dilute hydrochloric acid. When silver nitrate solution is added to the solution of the substance, a crystalline precipitate of silver nitrite is obtained, which dissolves in hot water, leaving in some cases a faint opalescence. That the substance does not contain any ammonium nitrate is shown by the fact that the amount of nitrogen yielded by the "urea" method is identical with that of the nitric oxide obtained by the Crum-Frankland method. The "ammonia" nitrogen in the salt, as estimated by the Nessler test, bears the ratio of $1: 1$ to the nitrogen in the acid radicle. The substance is therefore proved to be pure ammonium nitrite.

The salt may be kept undecomposed in an ordinary desiccator over concentrated sulphuric acid or in sealed tubes. If kept in a vacuum desiccator, the salt vaporises, and within two or three days the greater part is lost, and the odour of nitrous fumes, formed by the action of the sulphuric acid on the vaporised nitrite, is perceived on opening the desiccator.

* It was found by blank experiments that solid ammonium chloride commenced to sublime in small quantities when the temperature of the bath was above $140^{\circ}$ and the pressure was between 10 and $20 \mathrm{~mm}$. 
Ammonium nitrite volatilises in steam. A solution of the salt was placed in a distilling flask, and steam was admitted into it. The pump was worked, and after some time the distillate was tested, when appreciable quantities of ammonium nitrite were found in it.

We confirm Rây's observation (loc. cit.) that the re-sublimed salt does not explode on heating, although, as already pointed out, the salt sometimes decomposes with almost explosive violence as its concentrated solution just becomes solid.

\section{Vapour Density of Ammonium Nitrite.}

The question whether the sublimation of ammonium nitrite is really a case of sublimation or dissociation was left open by Rây (loc. cit.). In order to decide the point, we determined the vapour density of the salt according to Hofmann's method. Using chloroform vapour to heat the Hofmann tube, it was found that the solid substance was only partly vaporised, and with ethyl alcohol, also, it was found that some portion of the substance still remained solid. At $100^{\circ}$, using steam, the density of the resulting gas was found to be 12.7 . This result shows that at $100^{\circ}$ the salt almost entirely decomposes according to the usual equation:

$$
\begin{array}{r}
\mathrm{NH}_{4} \mathrm{NO}_{2}=\mathrm{N}_{2}+2 \mathrm{H}_{2} \mathrm{O} . \\
2 \text { vols. } 4 \text { vols. }
\end{array}
$$

The decomposition according to the above reaction, in which one molecular proportion of ammonium nitrite decomposes into two volumes of nitrogen and four volumes of water vapour, would give the vapour density of ammonium nitrite as $10 \cdot 6$, the density actually obtained being $12 \cdot 7$.

Chemical Laboratory, Rajshahi College, Rajshahi, Eastern Bengal, India. 